\title{
Frailty status, timely goals of care documentation and clinical outcomes in older hospitalised medical patients
}

Authors:

\author{
Ashwin Subramaniam, Ravindranath Tiruvoipati, Cameron Green, Velandai \\ Srikanth, Lionel Soh, Aun Chian Yeoh, Faisal Hussain, Michael Bailey, David \\ Pilcher
}

\section{Authors:}

1. Dr Ashwin Subramaniam (MBBS, MMed, FRACP, FCICM) Intensive Care Specialist, Frankston Hospital and The Bays Hospital Head of Acute Admission and Assessment Unit (during the study period) Adjunct Senior Lecturer, Peninsula Clinical School, Monash University

2. Professor Ravindranath Tiruvoipati MBBS, MS, MCh, FRCSEd, MSc, FCICM, EDIC, PhD Intensive Care Specialist, Frankston Hospital and Peninsula Private Hospital Professor, Peninsula Clinical School, Monash University

3. Mr Cameron Green (MSc)

ICU Research Coordinator, Frankston Hospital, (during the study period) Global Project Manager for REMAP-CAP Study, The Australian and New Zealand Intensive Care-Research Centre, School of Public Health and Preventive Medicine, Monash University, Melbourne, VIC

4. Prof Velandai Srikanth MBBS, FRACP, PhD

Geriatrician, Peninsula Health

Professor of Medicine, Peninsula Clinical School, Central Clinical School, Monash University

Adjunct Professor, Menzies Institute for Medical Research, Hobart, Tasmania NHMRC Practitioner Fellow

5. Mr Faisal Husain (BSc, MCA, MIS)

Business Intelligence Unit, Peninsula Health (during the study period)

6. Dr Lionel Soh (MBBS)

Medical Registrar, Frankston Hospital (during the study period)

7. Mr Aun Chian Yeoh (MBBS)

Medical Student, Monash University (during the study period)

8. Prof Michael Bailey (PhD, MSc(statistics), BSc(hons))

Head statistician, Australian and New Zealand Intensive Care Research Centre

9. Prof David Pilcher (MBBS MRCP(UK) FRACP FCICM)

Senior Intensive Care Specialist, The Alfred Hospital, Melbourne, VIC 3004

Clinical Lead Critical Care Network, Safer Care Victoria, Melbourne

Adjunct Clinical Professor, The Australian and New Zealand Intensive Care-Research Centre, School of Public Health and Preventive Medicine, Monash University, Melbourne, VIC

Chair, The Australian and New Zealand Intensive Care Society (ANZICS) Centre for Outcome and Resource Evaluation (CORE), 277 Camberwell Road, Camberwell, VIC 3124

Medical Advisor to DonateLife in Victoria

\section{Corresponding author:}

Dr Ashwin Subramaniam, Intensivist

Department of Intensive Care, Frankston Hospital

Frankston, Victoria 3199

Phone: +61 397847422

Facsimile: +61 397847398

Email: catchdrash@yahoo.com

This article has been accepted for publication and undergone full peer review but has not been through the copyediting, typesetting, pagination and proofreading process which may lead to differences between this version and the Version of Record. Please cite this article as doi: $10.1111 /$ imj.15032 


\title{
Frailty status, timely goals of care documentation and clinical outcomes in older hospitalised medical patients
}

\begin{abstract}
Objective: Hospitalised frail older patients are at risk of clinical deterioration. Early goals of care documentation (GOC) is vital to avoid futile/unwarranted interventions in the event of deterioration. We aimed to investigate the impact of frailty on timely GOC and its association with clinical outcomes in hospitalised older patients.
\end{abstract}

Design, setting, participants: Single-centre retrospective study of all medical patients aged $\geq 80$ years admitted to acute medical unit between $1 / 3 / 2015$ and 31/8/2015, with GOC derived from electronic records. Frailty was measured using Hospital Frailty Risk Score (HFRS) derived from hospital coding data.

Main Outcome Measures: Primary outcome compared proportions timely GOC within 72hours between frail $(H F R S \geq 5)$ and non-frail $(H F R S<5)$ patients. Exploratory secondary outcomes included in-hospital mortality, rapid response calls (RRCs), prolonged length of stay (LOS), and 28-day readmission rates.

Results: 529 (47.3\%) of the 1,118 admitted patients were frail. Timely GOC occurred in 50\% (559/1118), more commonly in frail patients $(283 / 529,53.5 \%)$ than non-frail patients $(276 / 589$, $46.9 \%), p=0.027$. Frailty was positively associated with timely GOC independent of age and sex $(\mathrm{OR}=1.28 ; 95 \%-\mathrm{Cl}=1.01-163 ; \mathrm{p}=0.041)$. In univariable analyses, timely $\mathrm{GOC}$ was associated with greater in-hospital mortality, RRCs, and hospital LOS in both frail and nonfrail patients (all $\mathrm{p}<0.05$ ); and greater 28-day readmissions only among frail patients $(p=0.028)$. Multivariable regression demonstrated timely GOC was associated only with inhospital mortality in both frail and non-frail patients, independent of age and sex.

Conclusion: Older frail hospitalised patients were more likely to have timely GOC than older non-frail patients. Timely GOC in such patients may avoid burdensome treatments. 


\section{Introduction}

The population of patients hospitalised in high-income countries has shifted from relatively young with a single diagnosis to being increasingly older with multiple comorbidities who undergo more complicated diagnostic procedures and treatment regimens. ${ }^{1}$ Older people (aged $\geq 65$ years ${ }^{2}$ ) are major users of acute health care ${ }^{3}$ with increasing utilization of critical care services. ${ }^{4}$ Some older people are susceptible to poorer outcomes ${ }^{5}$ over and above those expected on the basis of age or comorbidities. This increased vulnerability, termed as frailty, is thought to reflect a loss of physical, physiological and cognitive reserves to stressors. ${ }^{6}$

Since the development of cardiopulmonary resuscitation (CPR) in the 1960s for cardiac arrest, ${ }^{7}$ the practice of resuscitation has evolved mandating CPR unless there is a 'not for cardiopulmonary resuscitation' (NFR) order documented in the patient's file. NFR orders, with several names and formats, ${ }^{8}$ are important clinical documents that highlight any treatment limitations in case of clinical deterioration and rapid response call activation (RRC). Contrary to the misconception that they indicate a patient's imminent death to clinicians ${ }^{9}$ potentially compromising their care,${ }^{10}$ these vital documents address patient goals of care and preferences and provide a basis for clinical and ethical decision-making. ${ }^{11,12}$

Although age and primary diagnosis has relevance for initiating a goal of care document (GOC), ${ }^{10}$ it is good practice for patients to have such discussions with their general practitioners ${ }^{13}$ (advance care plans) and then to have those plans reviewed early in the admission and prior to discharge. However, when patients are admitted to hospital, physicians do not routinely initiate such discussions until late in the course of 
an illness. ${ }^{14-16}$ It is essential to have such conversations early during a patient's hospitalisation, ${ }^{17,18}$ with the patient and their loved ones, before clinical deterioration occurs. ${ }^{18}$ This allows them time to understand their illness, providing adequate time for clinicians to offer recommendations, and appropriately respond to queries and emotions in a non-emergent setting. ${ }^{19}$

GOC are highly relevant in acute medical units which serve a large number of older patients. ${ }^{18}$ Frail older people have more complex health needs and life-limiting conditions that predispose to sudden deterioration or cardiorespiratory arrest. ${ }^{12,20}$ Frailty, rather than age alone, may therefore be an important trigger for documenting GOC. To the best of our knowledge there are no studies investigating the association of frailty with the documentation and timing of GOC.

We aimed to investigate the relationship between frailty and timely GOC 17,18 documentation in consecutively admitted medical patients aged $\geq 80$ years. In addition, we studied whether the association between GOC documentation and clinical outcomes such as in-hospital mortality, RRC, prolonged LOS, and 28-day readmission rate were influenced by frailty status.

\section{Methods}

Design: Single centre retrospective cohort study.

Study setting: Acute Medical Unit (AMU) in a tertiary hospital located in Melbourne (Victoria, Australia). Frankston Hospital (part of Peninsula Health) is the sole metropolitan hospital for the Mornington Peninsula region. The proportion of people aged $\geq 65$ years in this catchment is $17.1 \%$ of the total population,,$^{21}$ which is higher than across Melbourne (16\%) and Victoria (13.8\%). Almost 35\% of the older population in this catchment are aged $\geq 80 .{ }^{22}$ The hospital opened a new AMU in February 2015 in which a policy was implemented that patients aged $\geq 75$ years or those with significant comorbidities must have early GOC documentation, even if there were no limitations in care.

Sample: Consecutive patients $\geq 80$ years admitted to the acute medical unit for at least 24 hours between March $1^{\text {st }}$ and August $31^{\text {st }}, 2015$ were included in the study. 
Definitions: Data were collected by review of medical records. GOC documents were defined as those that clearly stated plans either to institute or withhold CPR in the event of clinical deterioration. Timely GOC was defined as documentation within 72 hours of hospitalisation. Advance care plans (ACP) are legal documents, that express patient wishes and includes a Refusal of Treatment Certificate. We defined prolonged hospitalisations as acute hospital length of stay (LOS) $\geq 10$ days. ${ }^{23}$

Hospital Frailty Risk Score (HFRS): This tool for assessing frailty in hospitalised patients was used in this study ${ }^{24}$ is estimated using routine data based on the International Statistical Classification of Diseases and Related Health Problems, Tenth Revision (ICD-10) coding system obtained from the Australian-refined Diagnosis related groups (AR-DRG). ICD-10 codes used to estimate HFRS are summarised in supplementary table 1 . The resulting score is usually categorised as low-risk $(<5)$, intermediate-risk (5-15) and high-risk (>15) for frailty. ${ }^{24}$ For the purposes of this study, we categorised patients with HFRS score $\geq 5$ as frail and those with score $<5$ as nonfrail, ${ }^{24}$ and the frailty syndrome were based on ICD-10 codes. ${ }^{24,25}$

Outcomes: The primary outcome was the proportion of people with timely GOC documentation by frailty status. In addition, exploratory analyses were conducted according to frailty status to evaluate the association of timely GOC documentation with in-hospital mortality, RRC, acute prolonged hospital LOS (that excludes rehabilitation), and 28-day readmission (as reported in the electronic records of their subsequent admissions).

Statistical analysis: Statistical analysis was completed using SPSS (v.26, IBM).

Group comparisons were made using chi-square tests for proportions, student t-tests for normally distributed data and Mann-Whitney U-tests otherwise, with results presented as frequencies (\%), means (standard deviations) or medians (interquartile range) respectively. Multivariable logistic regression was conducted to investigate the relationship between exposure and outcomes controlling for age and sex with results reported as odds ratios $(95 \% \mathrm{Cl})$. All $\mathrm{p}$-values reported are two-tailed and threshold for statistical significance was set at $p<0.05$.

Ethical Approval: This project was approved as audit activity by Research Governance of Peninsula Health (HREC reference number LNR/59001/PH-2019). 
Informed consent was not required as this study was a retrospective review of data routinely collected for patient care.

\section{Results}

During the study period, 1,118 patients aged $\geq 80$ years were admitted, of whom 529 patients (47.3\%) were frail (HFRS $\geq 5$ ) and 589 (52.7\%) were non-frail. A comparison of demographic characteristics, diagnosis and ACPs at admission between groups are presented in table 1. Compared with the frail group, people with frailty were more likely to be female, aged $\geq 90$ years, and had conditions such as falls and fracture, incontinence and cognitive impairment. Neither the place of residence prior to admission nor the presence of ACPs (present only in approximately $7 \%$ of patients) differed between groups. Compared with those in the non-frail group, a lower proportion with frailty were discharged from acute care directly to their usual prehospital admission accommodation ( $32.3 \%$ vs $57.7 \%$; $p<0.001)$ and were more likely to be discharged to in-patient rehabilitation (46.1\% vs. $27.7 \%$; $p<0.001)$. AR-DRG for frail and non-frail groups are summarised in Supplementary Tables $2 \mathrm{a}$ and $2 \mathrm{~b}$. The frail group was more likely have greater acute LOS and in-hospital mortality than the non-frail group (comparisons not shown, but can be derived from information on Table 3).

Frailty and GOC Documentation: Figure 1 and Table 2 provides a breakdown of patient numbers by frailty and timely GOC documentation. GOC documentation occurred in $54 \%(604 / 1118)$ overall during their acute hospitalisation. Timely GOC occurring in $50 \%(559 / 1118)$, more commonly in the frail group $(283 / 529,53.5 \%)$ than in the nonfrail group $(276 / 589,46.9), p=0.027$. For people admitted from residential aged care facilities (RACFs), when compared with the non-frail group (96/175, 54.9\%), the proportions with any GOC recorded increased significantly in the frail group (112/158, 70.9\%), $\mathrm{p}=0.002$ during their acute hospital stay (Table 1).

In both frail and non-frail groups with timely GOC documentation (Table 2), the requirement for full resuscitation was recorded in a similar minority of patients $(\sim 12 \%)$, while treatment limitations were recorded in a similar majority $(\sim 75 \%)$. The frail group 
was more likely than the non-frail group to have GOC recorded as needing only wardlevel management such as intravenous (IV) fluids and antibiotics. The non-frail group was more likely than the frail group to have GOC expressing a need for ICU admission but with ceiling of care limited to non-invasive ventilation and vasopressor supports $(p=0.002)$. There was no difference between the groups with respect to GOC for palliative symptom management. In multivariable regression, frailty was positively associated with timely GOC documentation independent of age and sex (OR-1.28; 95\% Cl 1.01-163; $p=0.041)$.

Among frail patients, RRCs were more frequent in those with timely GOC documentation $(44 / 283,15.5 \%)$ than in those without a timely GOC $(22 / 246,8.9 \%)$ during hospitalisation, $p<0.001$. Similarly, RRCs amongst non-frail patients with timely GOC $(18 / 276,6.5 \%)$ were more frequent than in those without timely GOC (14/313, $4.5 \%), p=0.037$. GOC were initiated only after an RRC in 21 patients, the majority of whom were frail $(17 / 21,80.9 \%)$. Among those who had an RRC, in-hospital mortality was higher in frail patients $(27 / 65,41.5 \%)$ compared with non-frail patients (4/33, 12.1\%), $p=0.005$. Unplanned ICU admission following RRC was not different between frail and non-frail groups (1.1\% vs. $0.8 \% ; p=0.63)$.

\section{Timely GOC documentation and clinical outcomes stratified by frailty status:}

In univariable analyses (Table 3), timely GOC documentation was associated with greater in-hospital mortality, RRC activation, and hospital LOS in both frail and nonfrail groups (all $p<0.05$ ). Timely GOC was associated with greater readmission within 28 days only among the frail group $(p=0.028)$.

In both frail and non-frail groups, multivariable regression adjusted for age and sex (Table 4) showed similar directions of associations of timely GOC documentation with greater in-hospital mortality, RRC activation, LOS and readmission within 28 days, although they were statistically significant only for in-hospital mortality (in both groups) and RRC activation (only in the frail group). For in-hospital mortality, the magnitude of the association was greater in the non-frail group (OR 11.61, 95\% $\mathrm{Cl} 2.67-50.64)$ than in the frail group (OR 2.82, 95\%-Cl 1.49-5.32). 


\section{Discussion}

This single-centre retrospective cohort study revealed several important findings relating to the timeliness of $\mathrm{GOC}$, its relation to frailty and associated outcomes in older general medical inpatients. Timely GOC documentation occurred only in half the overall sample, and more frequently in frail older people independent of age and sex. Completion of GOC at any time during hospital stay was more likely in frail people admitted from RACFs than in those with less frailty from RACFs. Timely GOC documentation was also associated with in-hospital mortality independent of age and sex, both in the presence and absence of frailty.

While recommendations suggest timely GOC is vital, ${ }^{17}$ there is currently no consensus to define 'timely'. We chose a conservative period of 'within 72 hours of hospitalisation' to define 'timely'. ${ }^{17}$ The overall completion of GOC of $54 \%$ in our study was higher than previously reported estimates of 15 to $34 \%,{ }^{10,18,26}$ likely due to implementation of hospital policy that all patients aged $\geq 75$ years must have early GOC documentation when admitted to the AMU.

While it was evident that the presence of frailty may have influenced timely documentation of GOCs, it is not possible to be certain of the exact reasons that triggered the GOC due to the retrospective study design. The simplest explanation may be that clinical teams identified characteristics of frailty reasonably well, particularly in the context of severe illness which was likely to lead to a poor outcome. For example, the top admission diagnostic categories among frail people were those possibly considered less modifiable from a medical perspective - such as falls, dementia, delirium and renal failure - and carrying a high risk of death. Hence, such an anticipation of a poor outcome is likely to have driven the timeliness of GOC documentation, along with consideration of their general functioning, comorbidities, or patients and families requesting end-of-life discussions. ${ }^{27}$ Patients admitted from RACFs are usually considered frail by the clinical community. However, it appears that clinicians may have been differentiating those with greater frailty even in this subset, evidenced by timely GOC - although illness severity may be an unmeasured 
confounding factor in this argument. This apparently intrinsic ability of clinicians to identify frailty (as defined post-hoc using the HFRS), even in the absence of the routine use of a clinical frailty index, is particularly interesting. It speaks for the presence of judgement of frailty based on clinical experience, although the overall proportion with timely GOC documentation in frail people (53.5\%) indicates the need to have systems in place to better capture frailty in day-to-day clinical practice. The separation of groups based on frailty syndromes and the association of frailty generally with poorer outcomes also provide support for the construct validity of the HFRS, which has not been previously shown in an Australian population.

Prior studies have not demonstrated associations between timely GOC documentation, frailty and mortality. Unsurprisingly, older patients are considered to be high-risk for death, and hence are more likely to have GOC documented. ${ }^{26}$ Mortality rates were higher in frail patients, comparable with published evidence. ${ }^{24}$ Although we found that the odds of frail patients dying in-hospital with a timely GOC was nearly 3fold greater than in those without a timely GOC, these odds were much greater (nearly 12-fold) among non-frail patients with timely GOC. However, the latter group may have, by virtue of their illness severity may have created the need to have early GOC, a fact supported by their short mean time to death (2.9 days), which in turn may have reflected rapid illness progression. However, the wide confidence intervals and small numbers in the above analysis may suggest that the difference in magnitude of the association may in fact not be dissimilar.

In hospital settings, RRC are intended to improve patient care by identifying at-risk patients before deterioration into cardiac arrest, and planning appropriately graded institution of intensive care if required.$^{28}$ It is therefore important that GOCs happened before clinical deterioration. ${ }^{29}$ However, in previous work, approximately one-third of RRC have been found to occur for patients at their end-of-life. ${ }^{30}$ Frailty influences the trajectory of clinical deterioration,,$^{20}$ and in such people RRC may also be seen as a sentinel event that initiates a dialogue about GOC which might not occur otherwise. ${ }^{31-}$ ${ }^{35}$ Consistent with this, we found that $21.4 \%$ (21/98) had GOC implemented post-RRC, with $>80 \%(17 / 21)$ of these patients being frail, and $52.9 \%(9 / 17)$ dying during their 
hospitalisation. Delaying GOC documentation, especially after an RRC, or lack of GOC documentation, could be an indication of system failure. ${ }^{36,37}$ However, although RRCs may act as a trigger for GOC discussions, this may not be the most efficient use of resources. ${ }^{37}$ Recent guidelines from the Australian Committee for Safety and Quality in Health Care (ACSQHC) about comprehensive care may provide the impetus to improve the recording of GOC plans in hospital settings, ${ }^{38}$ by mandating systems to incorporate shared decision-making with patients early during the course of admission.

Limitations: This study has limitations that must be acknowledged. Firstly, the study was conducted in a single-centre, and the results may have been influenced by unmeasured factors such as illness severity and other hospital-specific policies, procedures and resource capability that drive clinical decision-making. Care must therefore be taken when generalizing the results of this study to other healthcare institutions, particularly smaller community and rural hospitals. Secondly, the retrospective study design meant that data collection was reliant on existing datasets and medical records. Thirdly, the predictive abilities of HFRS may not accurately capture complex patient characteristics that do not have standardised ICD-10 codes, including dynamic functional states, caregiver characteristics, and fluctuations influenced by acute illness. Moreover, ICD-10 coding may either be inaccurately recorded or may not properly capture the disease severity, this may affect the overall HFRS score. ${ }^{24}$ This may influence not only the prevalence of frailty in this sample, but also the magnitude of the associations seen with GOC. Assuming a random distribution of coding error, this misclassification may have attenuated the associations observed. Finally, only readmissions to the study hospital were captured and any patients presenting to other institutions may have been missed. Due to the geographic location of the study hospital as the sole public provider, we assume that most patients included in this study would have returned to our hospital for subsequent hospitalisations. Given the retrospective nature of the study and reliance on medical records alone, it was hard to capture important outcomes such as quality of life and functional status. 
Future prospective multicentric research is required to establish feasibility of timely GOC before RRC, its clinical implications in frail patients, and generalisability of findings. Such studies should be designed to capture the clinician's reasoning behind early GOC documentation and help understand impact of such documentation on the quality of life and functional outcomes that are important for patients.

\section{Conclusions}

Older frail hospitalised patients were found to be more likely to have timely goals of care documented than older non-frail patients. Timely GOC in such patients may avoid burdensome treatment and unnecessary RRC, while aiming to achieve a better quality of care towards their end-of-life. 


\section{Declarations of interest}

- We declare that we have no proprietary, financial, professional or other personal interest of any nature or kind in any product, service and/or company that could be construed as influencing the position presented in the submitted manuscript.

- This research did not receive any specific grant from funding agencies in the public, commercial, or not-for-profit sectors. 


\section{References}

1. Adhikari NK, Fowler RA, Bhagwanjee S, Rubenfeld GD. Critical care and the global burden of critical illness in adults. Lancet 2010;376:1339-46.

2. Ageing and health. 2018. (Accessed July 20, 2020, at https://www.who.int/newsroom/fact-sheets/detail/ageing-and-health.)

3. Rechel B, Grundy E, Robine JM, et al. Ageing in the European Union. Lancet 2013;381:1312-22.

4. Nguyen YL, Angus DC, Boumendil A, Guidet B. The challenge of admitting the very elderly to intensive care. Ann Intensive Care 2011;1:29.

5. Fisher C, Karalapillai DK, Bailey M, Glassford NG, Bellomo R, Jones D. Predicting intensive care and hospital outcome with the Dalhousie Clinical Frailty Scale: a pilot assessment. Anaesth Intensive Care 2015;43:361-8.

6. Clegg A, Young J, lliffe S, Rikkert MO, Rockwood K. Frailty in elderly people. Lancet 2013;381:752-62.

7. Kouwenhoven WB, Jude JR, Knickerbocker GG. Closed-chest cardiac massage. JAMA 1960;173:1064-7.

8. Levinson M, Mills A, Hutchinson AM, Heriot G, Stephenson G, Gellie A. Comparison of not for resuscitation (NFR) forms across five Victorian health services. Intern Med J 2014;44:671-5.

9. Sulmasy DP. Do patients die because they have DNR orders, or do they have DNR orders because they are going to die? Med Care 1999;37:719-21.

10. McNeill D, Mohapatra B, Li JY, et al. Quality of resuscitation orders in general medical patients. QJM 2012;105:63-8.

11. Kaldjian LC, Broderick A. Developing a policy for do not resuscitate orders within a framework of goals of care. Jt Comm J Qual Patient Saf 2011;37:11-9.

12. Pitcher D, Fritz Z, Wang M, Spiller JA. Emergency care and resuscitation plans. BMJ 2017;356:j876.

13. Tran M, Grant M, Clayton J, Rhee J. Advance care decision making and planning. Aust J Gen Pract 2018;47:753-7.

14. Davison SN. End-of-life care preferences and needs: perceptions of patients with chronic kidney disease. Clin J Am Soc Nephrol 2010;5:195-204.

15. Keating NL, Landrum MB, Rogers SO, Jr., et al. Physician factors associated with discussions about end-of-life care. Cancer 2010;116:998-1006.

16. Mack JW, Cronin A, Taback N, et al. End-of-life care discussions among patients with advanced cancer: a cohort study. Ann Intern Med 2012;156:204-10.

17. LeBlanc TW TJ. Discussing goals ofcare. UpToDate. Waltham, MA: UpToDate; 2020.

18. Mills A, Walker A, Levinson $M$, et al. Resuscitation orders in acute hospitals: A point prevalence study. Australas J Ageing 2017;36:32-7.

19. Dunlay SM, Strand JJ. How to discuss goals of care with patients. Trends Cardiovasc Med 2016;26:36-43.

20. So RKL, Bannard-Smith J, Subbe CP, et al. The association of clinical frailty with outcomes of patients reviewed by rapid response teams: an international prospective observational cohort study. Crit Care 2018;22:227.

21. Mornington Peninsula Shire: Population and age structure map. 2016. (Accessed July 21 2020, at https://forecast.id.com.au/mornington-peninsula/population-agestructure-map?CustomAgeFrom $=65 \&$ CustomAgeTo=85.) 
22. Aged Care. 2020. (Accessed July 21, 2020, at https://www.peninsulahealth.org.au/services/services-a-e/aged-care/.)

23. Chan $\mathrm{C}-\mathrm{L}$, Ting H-W, Huang H-T. The Definition of a Prolonged Intensive Care Unit Stay for Spontaneous Intracerebral Hemorrhage Patients: An Application with National Health Insurance Research Database. BioMed Research International 2014;2014:891725.

24. Gilbert T, Neuburger J, Kraindler J, et al. Development and validation of a Hospital Frailty Risk Score focusing on older people in acute care settings using electronic hospital records: an observational study. Lancet 2018;391:1775-82.

25. Soong J, Poots AJ, Scott S, et al. Quantifying the prevalence of frailty in English hospitals. BMJ Open 2015;5:e008456.

26. Shanmuganathan N, Li JY, Yong TY, Hakendorf PH, Ben-Tovim DI, Thompson CH. Resuscitation orders and their relevance to patients' clinical status and outcomes. QJM 2011;104:485-8.

27. Thomas RL, Zubair MY, Hayes B, Ashby MA. Goals of care: a clinical framework for limitation of medical treatment. Med J Aust 2014;201:452-5.

28. Bellomo R, Goldsmith D, Uchino S, et al. A prospective before-and-after trial of a medical emergency team. Med J Aust 2003;179:283-7.

29. Subramaniam A, Green C, Omair M, Soh L, Yeoh AC, Tiruvoipati R. Cost implications of avoidable rapid response call activations in older patients. $\mathrm{N} Z \mathrm{Z}$ Med J 2018;131:38-52.

30. Jones DA, Bagshaw SM, Barrett J, et al. The role of the medical emergency team in end-of-life care: a multicenter, prospective, observational study. Crit Care Med 2012;40:98-103.

31. Vazquez R, Gheorghe C, Grigoriyan A, Palvinskaya T, Amoateng-Adjepong Y, Manthous CA. Enhanced end-of-life care associated with deploying a rapid response team: a pilot study. J Hosp Med 2009;4:449-52.

32. Hillman K. Dying safely. Int J Qual Health Care 2010;22:339-40.

33. Chan PS, Khalid A, Longmore LS, Berg RA, Kosiborod M, Spertus JA. Hospital-wide code rates and mortality before and after implementation of a rapid response team. JAMA 2008;300:2506-13.

34. Chen J, Bellomo R, Flabouris A, et al. The relationship between early emergency team calls and serious adverse events. Crit Care Med 2009;37:148-53.

35. Parr MJ, Hadfield JH, Flabouris A, Bishop G, Hillman K. The Medical Emergency Team: 12 month analysis of reasons for activation, immediate outcome and not-forresuscitation orders. Resuscitation 2001;50:39-44.

36. Hillman KM, Lilford R, Braithwaite J. Patient safety and rapid response systems. Med J Aust 2014;201:654-6.

37. Subramaniam A, Botha J, Tiruvoipati R. The limitations in implementing and operating a rapid response system. Intern Med J 2016;46:1139-45.

38. Care ACoSaQiH. Implementing the Comprehensive Care Standard. Identifying goals of care. Sydney2019:18. 


\section{Legends for Tables and Figures}

\begin{tabular}{|l|l|}
\hline & Legend (figures attached individually in a separate document) \\
\hline Table 1. & Demographics of all newly admitted patients. \\
\hline Table 2. & Comparison of outcomes between frail and non-frail patients. \\
\hline Table 3. & $\begin{array}{l}\text { Univariable and Multivariable analyses - Relationship between frailty } \\
\text { and patient outcomes, after adjusting for age and sex. }\end{array}$ \\
\hline Figure 1. & $\begin{array}{l}\text { Flowchart demonstrating the difference in outcomes in frail and non-frail } \\
\text { patients who had early GOC documentation compared to those who had } \\
\text { a delayed GOC or no documentation of GOC during their } \\
\text { hospitalisation. }\end{array}$ \\
\hline
\end{tabular}


Table 1: Sample characteristics by frailty (presented as $\mathrm{n}(\%)$ or mean (range).

\begin{tabular}{|c|c|c|c|}
\hline & $\begin{array}{c}\text { Frail } \\
(\text { HRFS } \geq 5)\end{array}$ & $\begin{array}{c}\text { Non-Frail } \\
(\text { HFRS <5) }\end{array}$ & p-value \\
\hline $\mathbf{N}$ & $529(47.3 \%)$ & $589(52.3 \%)$ & \\
\hline Age & $86(83-90)$ & $86(83-89)$ & 0.06 \\
\hline$-\quad \geq 85$ years of age & $337(63.7 \%)$ & $358(60.8 \%)$ & 0.31 \\
\hline$-\quad \geq 90$ years of age & $150(28.4 \%)$ & $121(20.5 \%)$ & 0.002 \\
\hline \multicolumn{4}{|l|}{ Gender } \\
\hline - Male & $203(38.4 \%)$ & $274(46.5 \%)$ & \multirow{2}{*}{0.006} \\
\hline - $\quad$ Female & $326(61.6 \%)$ & $315(53.5 \%)$ & \\
\hline \multicolumn{4}{|l|}{ Marital Status } \\
\hline - $\quad$ Married/De facto & $202(38.2 \%)$ & $216(36.7 \%)$ & \multirow{4}{*}{0.73} \\
\hline - $\quad$ Single & $43(8.1 \%)$ & $54(9.2 \%)$ & \\
\hline - $\quad$ Widowed & $283(53.5 \%)$ & $316(53.7 \%)$ & \\
\hline - $\quad$ No information & $1(0.2 \%)$ & $3(0.5 \%)$ & \\
\hline Charlson Comorbidity Index & $5(4-6)$ & $5(4-6)$ & 0.014 \\
\hline \multicolumn{4}{|l|}{ Normal Residence Prior to Admission } \\
\hline - $\quad$ Home / Private accommodation / Retirement Village & $347(65.6 \%)$ & $401(68.1 \%)$ & 0.38 \\
\hline - $\quad$ Residential aged care facilities & $158(30.0 \%)$ & $175(29.7 \%)$ & 0.85 \\
\hline - $\quad$ Not specified & $24(4.4 \%)$ & $13(2.2 \%)$ & 0.06 \\
\hline \multicolumn{4}{|l|}{ Discharge Destination } \\
\hline - Home / Private accommodation / Retirement Village & $171(32.3 \%)$ & $340(57.7 \%)$ & $<0.001$ \\
\hline - $\quad$ Residential aged care facilities & $56(10.6 \%)$ & $63(10.7 \%)$ & 0.95 \\
\hline - $\quad$ Rehabilitation & $244(46.1 \%)$ & $163(27.7 \%)$ & $<0.001$ \\
\hline Unknown & $1(0.2 \%)$ & $2(0.3 \%)$ & 0.63 \\
\hline Advance care plan at admission & $40(7.6 \%)$ & $46(7.8 \%)$ & 0.88 \\
\hline Presence of frailty related syndrome $(s)^{\wedge \wedge}$ & $292(55.2 \%)$ & $157(26.7 \%)$ & $<0.001$ \\
\hline - $\quad$ Falls and fracture & $75(14.2 \%)$ & $34(5.8 \%)$ & $<0.001$ \\
\hline - $\quad$ Cognitive impairment & $65(12.3 \%)$ & $22(3.7 \%)$ & $<0.001$ \\
\hline Incontinence & $59(11.2 \%)$ & $9(1.5 \%)$ & $<0.001$ \\
\hline Functional dependence & $40(7.6 \%)$ & $44(7.5 \%)$ & 0.95 \\
\hline - $\quad$ Mobility problems & $34(6.4 \%)$ & $32(5.4 \%)$ & 0.48 \\
\hline - $\quad$ Pressure ulcers & $17(3.2 \%)$ & $15(3.2 \%)$ & 0.50 \\
\hline Anxiety/depression & $5(0.9 \%)$ & $3(0.5 \%)$ & 0.39 \\
\hline \multicolumn{4}{|c|}{ Top 6 AR-DRG Admission diagnosis / syndrome complexes for Frail patients } \\
\hline - Falls, Fractures and injuries* & $79(15.2 \%)$ & $49(8.5 \%)$ & 0.001 \\
\hline Dementia (B63Z) & $38(7.3 \%)$ & $15(2.6 \%)$ & $<0.001$ \\
\hline - $\quad$ Delirium (B64A, B64B) & $24(4.6 \%)$ & $5(0.9 \%)$ & $<0.001$ \\
\hline - $\quad$ Kidney failure (L60A, L60B, L60C) & $18(3.5 \%)$ & $4(0.7 \%)$ & 0.001 \\
\hline - $\quad$ CVA (B69A, B69B), TIA (B70A, B70B, B70C, B70D) & $14(2.7 \%)$ & $11(1.9 \%)$ & 0.38 \\
\hline - $\quad$ Cellulitis (J12A, J12C, J60A, J60B, J64A, J64B) & $12(2.2 \%)$ & $10(1.7 \%)$ & 0.86 \\
\hline \multicolumn{4}{|c|}{ Top 6 AR-DRG Admission diagnosis / syndrome complexes for Non-Frail Patients } \\
\hline - $\quad$ Lower Respiratory infections ${ }^{* *}$ & $50(9.6 \%)$ & $85(14.7 \%)$ & 0.010 \\
\hline - $\quad$ Heart failure (E64B, F62A, F62B, F62C) & $17(3.3 \%)$ & $58(10.1 \%)$ & $<0.001$ \\
\hline - $\quad$ Gastrointestinal related problems & $33(6.4 \%)$ & $51(8.8 \%)$ & 0.12 \\
\hline - $\quad$ Orthopaedic conditions $^{\wedge}$ & $33(6.4 \%)$ & $50(8.7 \%)$ & 0.15 \\
\hline - $\quad$ COPD (E65A, E65B) & $10(1.9 \%)$ & $46(8.0 \%)$ & $<0.001$ \\
\hline - $\quad$ Coronary syndromes $\#$ & $6(1.2 \%)$ & $27(4.7 \%)$ & 0.001 \\
\hline
\end{tabular}


CVA - cerebrovascular accident, TIA, transient ischaemic attack, COPD, chronic obstructive pulmonary disease AR-DRG (Australian Refined Diagnosis Related Groups (AR-DRGs)

* B78A, B78B, B78C, B79B, B80A, B80B, E66A, E66B, I03A, I03B, 161A, I63A, I63B, I71A, 171B, 172A, I74A, I74B,

I75A, 175B, 176A, I76B, I77A, 177B, I78A, I78B, I79A, I80Z, I81Z, J65A, J65B, X60A, X60B

** E67A, E67B, E68A, E73A, E73B, E75A, E75B

\# 801A, F21A, G01A, G02A, G12A, G47A, G47B, G60A, G60B, G61A, G61B, G64A, G65A, G66A, G67A, G67B, G70A, G70B, H08A, H40A, H43A, H61A, H61B, H61C, H62A, H64A, H64B

\#\# F60A, F60B, F66B, F72A, F72B, F74A, F74B

$\wedge$ I68A, I68B, I69A, I69B, I71A, I71B, I72A, I76A, I76B, I81A

$\wedge \wedge$ Frailty syndrome is based on ICD-10 codes defined in Soong et al (2015) ${ }^{43}$ and Gilbert et al (2018) ${ }^{21}$

* Cognitive impairment covers delirium (ICD-10 code F05), dementia (F00-F04, R41, B63Z) and senility (R54)

(Supplementary Table 1)

Please refer Supplemental tables 2 and 3 for the complete list of AR-DRG for frail and non-frail patients respectively. 
Table 2: Comparison of timely GOC documentation and related variables between frail and non-frail groups

\begin{tabular}{|c|c|c|c|}
\hline & $\begin{array}{c}\text { Frail } \\
(\text { HRFS } \geq 5) \\
(n=529)\end{array}$ & $\begin{array}{c}\text { Non-Frail } \\
(\text { HFRS <5) } \\
(n=589)\end{array}$ & p-value \\
\hline \multicolumn{4}{|l|}{ Primary Outcome } \\
\hline - $\quad$ GOC Within 72 hours of hospital admission & $283(53.5 \%)$ & $276(46.9 \%)$ & 0.027 \\
\hline \multicolumn{4}{|l|}{ Other GOC variables of interest } \\
\hline 1. GOC during hospital admission & $318(60.1 \%)$ & $286(48.6 \%)$ & $<0.001$ \\
\hline \multicolumn{4}{|l|}{ 2. GOC Status } \\
\hline - $\quad$ Full resuscitation & $36(11.3 \%)$ & $38(13.3 \%)$ & 0.46 \\
\hline - $\quad$ Limited resuscitation & $238(74.8 \%)$ & $217(75.9 \%)$ & 0.77 \\
\hline $\begin{array}{l}\text { - NFR, but for intubation, vasopressors and } \\
\text { CRRT }\end{array}$ & $15(4.7 \%)$ & $8(3.0 \%)$ & 0.22 \\
\hline - $\quad$ NFR and NFI, but for vasopressors and NIV & $87(27.4 \%)$ & $112(39.2 \%)$ & 0.002 \\
\hline $\begin{array}{ll}\text { - } & \text { NFR, only for active ward level } \\
& \text { management (iv fluids, antibiotics) }\end{array}$ & $136(42.7 \%)$ & $97(33.7 \%)$ & 0.026 \\
\hline - $\quad$ Symptomatic management (palliative care) & $44(13.9 \%)$ & $31(10.8 \%)$ & 0.27 \\
\hline
\end{tabular}


Table 3: Univariable associations between timely GOC and clinical outcomes of interest

\begin{tabular}{|c|c|c|c|}
\hline & $\begin{array}{c}\text { GOC within } \\
72 \text { hours } \\
(n=559)\end{array}$ & $\begin{array}{c}\text { No GOC within } \\
72 \text { hours } \\
(n=559)\end{array}$ & p-value \\
\hline 1. In-hospital mortality & $62(11.1 \%)$ & $16(2.9 \%)$ & $<0.001$ \\
\hline - Frail & $43(7.7 \%)$ & $14(2.5 \%)$ & 0.002 \\
\hline - Non-Frail & $19(3.4 \%)$ & $2(0.4 \%)$ & $<0.001$ \\
\hline 2. Rapid response call during admission & $62(11.1 \%)$ & $36(6.4 \%)$ & $<0.001$ \\
\hline - Frail & $44(7.9 \%)$ & $22(3.9 \%)$ & 0.001 \\
\hline - Non-Frail & $18(3.2 \%)$ & $14(2.5 \%)$ & 0.037 \\
\hline 3. Hospital LOS; days (median, IQR) & $5.7(2.6-7.7)$ & $3.2(1.7-6.1)$ & 0.001 \\
\hline - Frail & $5.7(3.3-9.1)$ & $4.8(2.2-8.5)$ & $<0.001$ \\
\hline - Non-Frail & $3.6(1.8-6.0)$ & $2.6(1.4-4.7)$ & $<0.001$ \\
\hline 4. Readmission within 28 days & $53(9.5 \%)$ & $32(5.7 \%)$ & 0.26 \\
\hline - Frail & $27(4.8 \%)$ & $8(1.4 \%)$ & 0.028 \\
\hline - Non-Frail & $26(4.7 \%)$ & $24(4.3 \%)$ & 1.00 \\
\hline
\end{tabular}


Table 4: Multivariable regression of relationship between timely GOC and outcomes adjusted for age and sex.

\begin{tabular}{|l|c|c|c|c|}
\hline \multirow{2}{*}{} & \multicolumn{4}{|c|}{ Multivariable Analysis } \\
\cline { 2 - 5 } & \multicolumn{2}{|c|}{ Frail } & Non-Frail \\
\cline { 2 - 5 } & OR (95\% Cl) & p-value & OR (95\% Cl) & p-value \\
\hline In-hospital Mortality & $2.82(1.49-5.32)$ & $<0.001$ & $11.61(2.67-50.64)$ & $<0.001$ \\
\hline Rapid response call activation & $1.96(1.13-3.39)$ & 0.016 & $1.57(0.76-3.24)$ & 0.23 \\
\hline Prolonged hospital LOS* & $1.08(0.69-1.67)$ & 0.74 & $0.84(0.49-1.79)$ & 0.84 \\
\hline Readmission within 28 days & $1.48(0.88-2.48)$ & 0.14 & $1.29(0.81-2.08)$ & 0.29 \\
\hline $\begin{array}{l}\text { * Defined as } \geq 10 \text { days } \\
\text { GOC - Goals of Care; OR - odds ratio; Cl - confidence intervals; LOS - length of stay }\end{array}$ \\
\hline
\end{tabular}


Figure 1: Flowchart demonstrating patient numbers for variables of interest by frailty and timely GOC status.

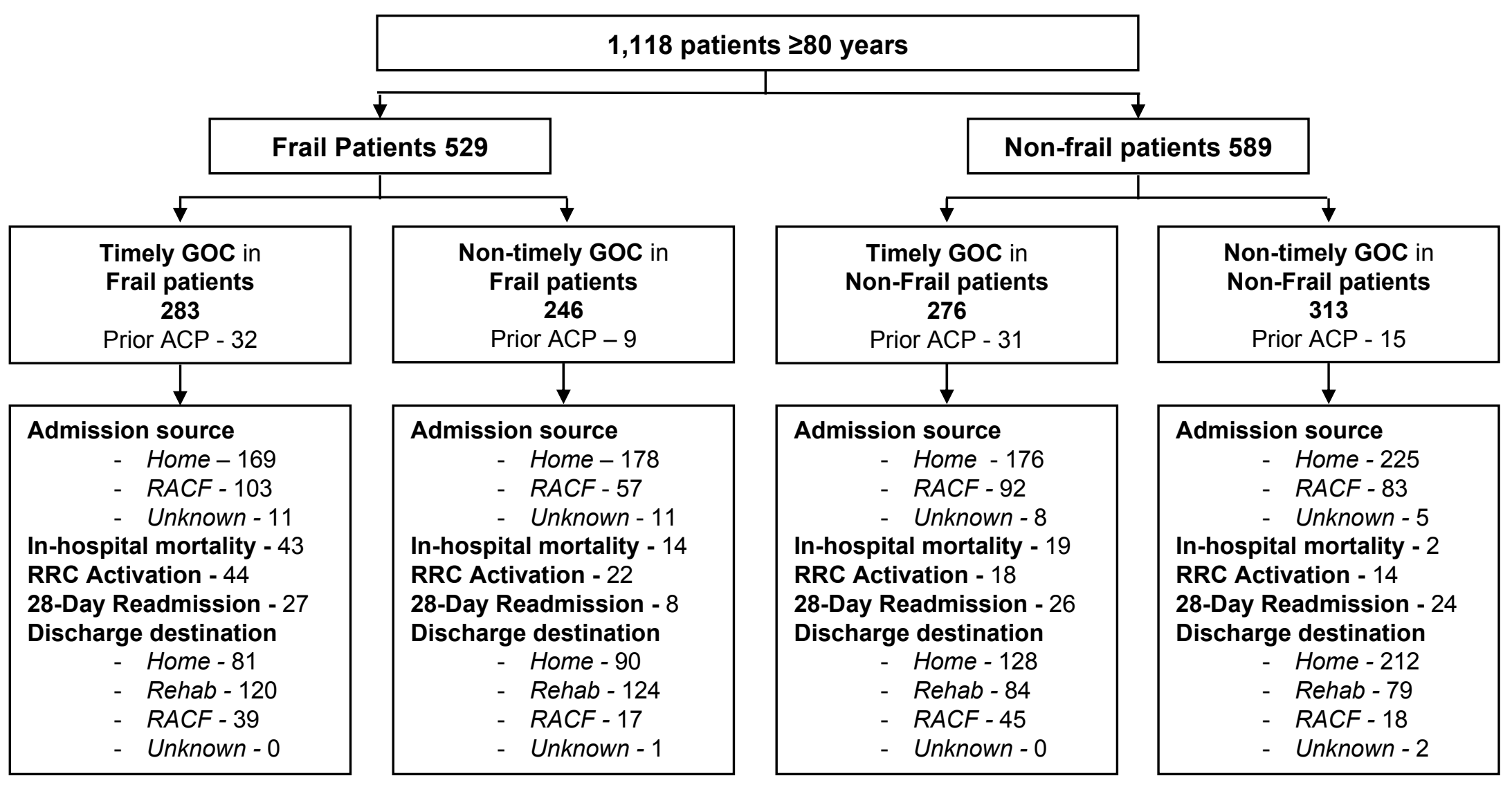

21 patients had GOC after RRC, 80.9\% (17/21) in frail and 19.1\% (4/21) in non-frail patients

$29.4 \%(5 / 17)$ of frail patients required ICU post-RRC; $52.9 \%$ (9/17) patients who had GOC post-RRC died

GOC - Goals of Care Documentation; ACP - advanced care plans, RACF - Residential Aged Care Facilities, RRC - Rapid response call activations; Rehab -

rehabilitation 